\title{
Kinetic and equilibrium studies on adsorption of Reactive Blue 19 dye from aqueous solutions by nanohydroxyapatite adsorbent
}

\author{
Gabriela Ciobanu*, Simona Barna, Maria Harja \\ "Gheorghe Asachi" Technical University of lasi, Romania \\ Faculty of Chemical Engineering and Environmental Protection \\ *Corresponding author's e-mail: gciobanu03@yahoo.co.uk
}

\begin{abstract}
Keywords: Reactive Blue 19 dye, hydroxyapatite, adsorption.
Abstract: In the present study the adsorption of Reactive Blue 19 dye on the hydroxyapatite (HAp) nanopowders was investigated. The batch adsorption experiments were performed by monitoring the adsorbent dosage, contact time, dye solution concentration, $\mathrm{pH}$ and temperature. $\mathrm{At} \mathrm{pH} 3$ and $20^{\circ} \mathrm{C}$, high dye removal rates of about $95.58 \%$ and $86.95 \%$ for the uncalcined and calcined nanohydroxyapatites, respectively, were obtained. The kinetic studies indicated the dye adsorption onto nanohydroxyapatite samples to follow a pseudo-second order model. The Langmuir isotherm was found to be the best to represent the equilibrium with experimental data. The maximum adsorption capacity of uncalcined and calcined nanohydroxyapatite samples has been found to be $90.09 \mathrm{mg} / \mathrm{g}$ and $74.97 \mathrm{mg} / \mathrm{g}$, respectively.
\end{abstract}

\section{Introduction}

The water pollution with synthetic dyes is connected with the chemical/biochemical oxygen demand, suspended solids, toxicity and color (Hao et al. 2000). Reactive dyes are used for dyeing cellulosic fibers (cotton), protein fibers (wool) and nylon. After dyeing processes, various amounts of dyes remain in wastewater (Webber and Stickney 1993). Some reactive dyes are reported to cause allergy, dermatitis, cancer and mutations in the human organism. Therefore, the dyes removal from effluents before being released into natural water is very important. Various techniques based on the physical, chemical, electrical and biological processes were developed, being used to eliminate reactive dyes from aqueous solutions (Forgacs et al. 2004, Bina et al. 2012). Among the above mentioned methods, adsorption can produce high quality water, being a simple, non-toxic and a low-cost method for dye removal from wastewaters (Allen and Koumanova 2005). Numerous adsorbents have been used for reactive dyes elimination from wastewater, such as activated carbon, natural/synthetic clay, fly ash, polymeric adsorbents, etc. (Ciobanu et al. 2008, Harja et al. 2011, Kahraman et al. 2012, Kaušpédienè et al. 2013). Currently, there is a growing interest in using low-cost, eco-friendly and non-conventional materials as an alternative to traditional adsorbents (Gupta et al. 2009).

The hydroxyapatite, $\mathrm{Ca}_{10}\left(\mathrm{PO}_{4}\right)_{6}(\mathrm{OH})_{2}(\mathrm{HAp})$, is a calcium phosphate ceramic with important applications in medicine and chemistry fields (Dorozhkin 2009). The HAp is expected to be a promising adsorbent due to its specific structure conferring ionic exchange property and adsorption affinity towards many polluting substances (Elliott 1994). In recent years, some applications of the HAp in adsorption of heavy metal ions, dyes and other organic compounds have been investigated and the results showed that the HAp shows attractive adsorption abilities (Lin et al. 2009, Ciobanu et al. 2009, Ciobanu et al. 2013, Ciobanu et al. 2014). Although some concerns have been focused on the Reactive Blue 19 adsorption on several adsorbents (Xue et al. 2009, Madrakian et al.2012), no such data have been reported for HAp as adsorbent until now. Therefore, the present study is aimed to investigate the Reactive Blue 19 adsorption on HAp under various experimental conditions. The study consists of a characterization of the adsorbents and the determination of the factors affecting the adsorption, including the solution $\mathrm{pH}$, adsorbent dose, dye concentration, contact time and temperature. The isotherm and kinetic investigations were carried out to estimate the Reactive Blue 19 dye adsorption on nanohydroxyapatite.

\section{Experimental}

\section{Materials}

$\mathrm{Ca}\left(\mathrm{NO}_{3}\right)_{2} \cdot 4 \mathrm{H}_{2} \mathrm{O},\left(\mathrm{NH}_{4}\right)_{2} \mathrm{HPO}_{4}, \mathrm{HNO}_{3}, \mathrm{NaOH}$ and Reactive Blue 19 dye were purchased by Sigma-Aldrich (Germany). All chemicals and reagents were of analytical grade. Reactive Blue 19 (RB19, Remazol Brilliant Blue R; $\mathrm{C}_{22} \mathrm{H}_{16} \mathrm{~N}_{2} \mathrm{Na}_{2} \mathrm{O}_{11} \mathrm{~S}_{3}$; molecular weight: 626.5; CI 61200; $\lambda_{\max }=595 \mathrm{~nm}$ ), a recalcitrant anthraquinonic dye, was selected in this study as a model of anionic dye for the adsorption experiments. It 
has one vinyl sulfonyl group $\left(-\mathrm{SO}_{2}-\mathrm{CH}_{2}-\mathrm{CH}_{2}-\mathrm{OSO}_{3} \mathrm{Na}\right)$ on the monobenzene ring and one sulfonic group $\left(-\mathrm{SO}_{3} \mathrm{Na}\right)$ on the anthraquinone ring (Fig. 1).<smiles>CS(=O)(=O)c1cccc(Nc2cc(S(=O)(=O)O[Na])c(N)c3c2C(=O)c2ccccc2C3=O)c1</smiles>

Fig. 1. Chemical structure of Reactive Blue 19 dye

\section{Preparation of nanohydroxyapatite}

The wet-chemical precipitation method was used to synthesize the HAp nanopowders (Ciobanu et al. 2009). An aqueous solution of $250 \mathrm{~mL}$ of $\mathrm{Ca}\left(\mathrm{NO}_{3}\right)_{2} \cdot 4 \mathrm{H}_{2} \mathrm{O}(0.01 \mathrm{M})$ was added drop-wise to an appropriate amount of $\left(\mathrm{NH}_{4}\right)_{2} \mathrm{HPO}_{4}(0.06 \mathrm{M})$ aqueous solution to achieve predetermined $\mathrm{Ca} / \mathrm{P}$ atomic ratio of 1.67. The solution was adjusted to $\mathrm{pH} 10.5$ by adding small portions of $1 \mathrm{M} \mathrm{NaOH}$ solution. The suspension was matured for $3 \mathrm{~h}$ at approximately $60^{\circ} \mathrm{C}$ under magnetic stirring. After that, the white powder was removed from the solution, washed with deionized water and dried at $110^{\circ} \mathrm{C}$ for $24 \mathrm{~h}$. Half of the powder obtained was calcinated at $850^{\circ} \mathrm{C}$ in order to increase their crystallinity. The uncalcined and calcined HAp were labeled sample HA-uc and sample HA-c, respectively.

\section{Samples characterization}

The phase composition of the HAp powders was characterized by X-ray diffraction (XRD) with X'PERT PRO MRD (PANalytical, Netherlands) diffractometer using monochromatic $\mathrm{CuK} \alpha$ radiation $(\lambda=0.15418 \mathrm{~nm})$. The average crystallite size $(D)$ of the HAp powders was calculated from XRD data by the Scherrer equation, using the peak at $2 \theta=25.9^{\circ}$ for (002) reflection. The morphology and chemical composition of samples were studied by scanning electron microscopy (SEM) coupled with energy dispersive X-ray spectroscopy (EDX) with QUANTA 200 3D (FEI, Netherlands) electronic microscope. Silver sputtering was used to make the coating surfaces conductive for the SEM investigations. The specific surface areas were evaluated by fitting the BrunauerEmmett-Teller (BET) equation to the $\mathrm{N}_{2}$ adsorption isotherms recorded by Quantachrome Nova 2200e Win2 (Quantachrome, Germany) apparatus. The $\mathrm{pH}$ at the point of zero charge $\left(\mathrm{pH}_{p z c}\right)$ of the HAp samples was determined by the $\mathrm{pH}$ drift method (Khan and Sarwar 2007). All pH measurements were realized with a multi-parameter Consort C831 (CONSORT, Belgium) apparatus.

\section{Batch adsorption experiments}

A stock solution (1000 mg/L) of RB19 dye was prepared using deionized water. Various dye solutions with different initial concentrations were prepared by diluting the stock dye solution. The $\mathrm{pH}$ of dye solutions was adjusted with $0.1 \mathrm{M} \mathrm{NaOH}$ or $\mathrm{HNO}_{3}$. The batch adsorption experiments were carried out by placing $100 \mathrm{~mL}$ of the corresponding dye solution and a known amount of the adsorbent into conical flasks. The flasks were then agitated at $200 \mathrm{rpm}$ for a given time and temperature by means of an orbital shaker. After a pre-determined contact time, the supernatant was centrifuged at $5000 \mathrm{rpm}$ for $10 \mathrm{~min}$ and analyzed for dye concentration determination. The effect of the contact time (0-24 h), $\mathrm{pH}(2-11)$, initial dye concentration (0.4-100 $\mathrm{mg} / \mathrm{L})$, adsorbent dose (1-20 g/L) and temperature $\left(20-60^{\circ} \mathrm{C}\right)$ on the dye adsorption was studied. The RB19 dye concentration in the filtrate solution was determined from its UV-Vis absorbance characteristic by the calibration method with UV-Vis Jasco V-550 (JASCO, Japan) spectrophotometer at a $592 \mathrm{~nm}$ wavelength. The dye adsorption capacity $\left(q_{t}, \mathrm{mg} / \mathrm{g}\right)$ and the removal rate $(R \%)$ referred to also as removal efficiency were calculated by means of the following relationships:

$$
\begin{aligned}
q_{t} & =\frac{C_{0}-C_{t}}{m} \cdot V \\
R \% & =\frac{C_{0}-C_{t}}{C_{0}} \cdot 100
\end{aligned}
$$

where $C_{0}$ and $C_{t}(\mathrm{mg} / \mathrm{L})$ depicts the dye concentration in the solution before and after adsorption, $V(\mathrm{~L})$ is the volume of solution and $m(\mathrm{~g})$ is the mass of the adsorbent. All experiments were run three times and the average results were used to data analysis.

\section{Theory}

\section{Adsorption kinetics models}

The adsorption process order and the rate constant were estimated by applying the pseudo-first order kinetic, pseudo-second order kinetic and intraparticle diffusion models.

The pseudo-first order kinetic model is expressed as (Lagergren 1898):

$$
\log \left(q_{e}-q_{t}\right)=\log q_{e}-\frac{k_{1}}{2.303} \cdot t
$$

where $q_{e}$ and $q^{t}(\mathrm{mg} / \mathrm{g})$ are the adsorption capacity at equilibrium and at time of $t(\mathrm{~min}), k_{1}\left(\mathrm{~min}^{-1}\right)$ is the pseudo first-order rate constant of adsorption. The values of $k_{1}$ and $q_{e}$ were calculated from the plot of $\log \left(q_{e}-q_{t}\right)$ versus $t$.

The pseudo-second order kinetic model is expressed as (Ho and McKay 1998):

$$
\frac{t}{q_{t}}=\frac{1}{k_{2} \cdot q_{e}^{2}}+\frac{1}{q_{e}} \cdot t
$$

where $k_{2}(\mathrm{~g} / \mathrm{mg} \cdot \mathrm{min})$ is the pseudo-second order rate constant of adsorption. The values of $k_{2}$ and $q_{e}$ were calculated from the plot of $t / q_{\mathrm{t}}$ versus $t$.

The intraparticle diffusion model is expressed as (Weber and Morris 1963):

$$
q_{t}=k_{i d} \cdot t^{1 / 2}+c
$$


where $k_{i d}\left(\mathrm{mg} / \mathrm{g} \cdot \mathrm{min}^{1 / 2}\right)$ is the intraparticle diffusion rate constant and $c(\mathrm{mg} / \mathrm{g})$ is the intercept. The values of $k_{i d}$ and $c$ were calculated from the plot of $q_{t}$ versus $t^{1 / 2}$.

The linear form of Arrhenius equation is expressed as:

$$
\ln k=\ln A-\frac{E_{a}}{R T}
$$

where $E_{a}(\mathrm{~kJ} / \mathrm{mol})$ is the activation energy of adsorption, $k$ is the rate constant of adsorption, $A(\mathrm{~g} / \mathrm{mg} \cdot \mathrm{min})$ is the temperature independent factor, $R(8.314 \mathrm{~J} / \mathrm{mol} \cdot \mathrm{K})$ is the universal gas constant and $T(\mathrm{~K})$ is the temperature. The rate constant of adsorption $(k)$ is either $k_{1}$ (pseudo first-order rate constant) or $k_{2}$ (pseudo-second order rate constant) obtained from the best fitting kinetic model. The value of $E_{a}$ was calculated from the plot of $\ln k$ versus $1 / T$. The magnitude of $E_{a}$ is used for differentiating between physical and chemical adsorptions. The physical adsorption reactions are reversible, the equilibrium is attained rapidly and the energy requirements are thus smaller $(5-40 \mathrm{~kJ} / \mathrm{mol})$. The chemical adsorption is specific, it involves stronger forces requiring thus higher activation energies (40-800 kJ/mol) (Unuabonah et al. 2007).

\section{Adsorption isotherms}

The results obtained from the equilibrium adsorption experiments were analyzed according to the Langmuir and Freundlich isotherm models and the model with higher correlation coefficient $\left(R^{2}\right)$ chosen.

The linear form of the Langmuir equation is written as (Langmuir 1916):

$$
\frac{1}{q_{e}}=\frac{1}{q_{m}}+\frac{1}{K_{L} \cdot q_{m}} \cdot \frac{1}{C_{e}}
$$

where $q_{m}(\mathrm{mg} / \mathrm{g})$ is the maximum adsorption capacity according to Langmuir monolayer adsorption and $K_{L}(\mathrm{~L} / \mathrm{mg})$ is the Langmuir equilibrium constant. The values of $q_{m}$ and $K_{L}$ were calculated from the plot of $1 / q_{e}$ versus $1 / C_{e}$.

The favorability of the dye adsorption process on adsorbent surfaces was confirmed by using a method applied by Weber and Chakravorti (Weber and Chakravorti 1974) suggesting the nature of an isotherm to depend on the obtained value of the separation factor $\left(R_{L}\right)$ also referred to as equilibrium parameter. $R_{L}$ is a dimensionless constant derived from the Langmuir expression and can be calculated by following equation:

$$
R_{L}=\frac{1}{1+K_{L} \cdot C_{0}}
$$

where $C_{0}(\mathrm{mg} / \mathrm{L})$ is the is the highest initial dye concentration in the solution. $R_{\mathrm{L}}$ values indicate that the adsorption process is irreversible $\left(R_{\mathrm{L}}=0\right)$, favorable $\left(0<R_{L}<1\right)$, linear $\left(R_{L}=1\right)$ or unfavorable $\left(R_{L}>1\right)$ (Weber and Chakravorti 1974).

The linear form of the Freundlich equation is written as (Freundlich 1906):

$$
\log q_{e}=\log K_{F}+\frac{1}{n_{F}} \cdot \log C_{e}
$$

where $K_{F}\left(\mathrm{mg}^{(1-1 / \mathrm{n})} \cdot \mathrm{L}^{1 / \mathrm{n}} / \mathrm{g}\right)$ and $n_{F}$ are Freundlich constants. The values of $K_{F}$ and $n_{F}$ were calculated from the plot of $\log$ $q_{e}$ versus $\log C_{e}$. The $K_{F}$ constant is related to the maximum amount adsorbed and it is a measure of the binding energy between the adsorbate molecule and the adsorbent surface. The values of $n_{F}$ between 1 and 10 indicate the favorable adsorption condition. The $1 / n_{F}$ values ranging between 0 and 1 represent a measure of the adsorption intensity or the surface heterogeneity that may become more heterogeneous when $1 / n_{F}$ gets close to zero. The $1 / n_{F}<1$ value suggests a normal Langmuir isotherm while $1 / n_{F}>1$ is indicative of cooperative adsorption (Ho and McKay 1998).

\section{Results and discussion}

\section{Characterization of absorbents}

Fig. 2 shows the XRD profiles for uncalcined (HA-uc) and calcined (HA-c) samples. Both uncalcined (HA-uc) and calcined (HA-c) samples have the diffraction lines characteristic of HAp, in good agreement with the JCPDS Data Card 09-0432 (HAp standard). In the case of HA-uc sample, the XRD pattern shows that the HAp has formed as a poorly crystalline phase because this sample remained only as uncalcined dried state. Moreover, in the case of the HA-c sample, the diffraction peaks are thinner indicating an increase in the crystallite size. The average crystallite size calculated by the Scherrer equation for the HA-uc and HA-c samples was of $49 \mathrm{~nm}$ and $57 \mathrm{~nm}$, respectively.

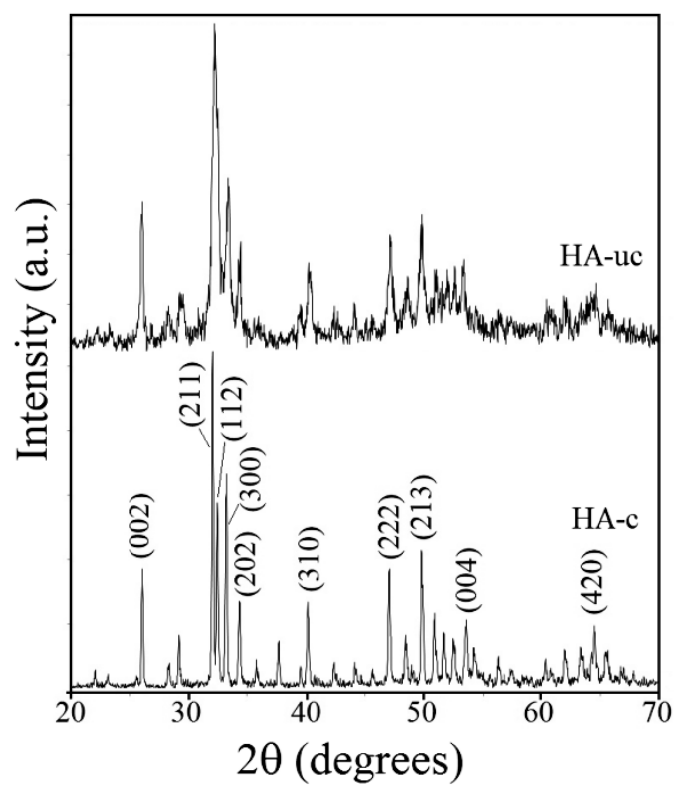

Fig. 2. XRD patterns of HA-uc and HA-c samples

The EDX analysis (figure not shown) confirms the presence of $\mathrm{Ca}, \mathrm{P}$, and $\mathrm{O}$ in the apatite crystallites. The $\mathrm{Ca} / \mathrm{P}$ mole ratios were of 1.682 and 1.665 for the HA-uc and HA-c samples, respectively, which corresponds to the stoichiometric HAp (Raynaud et al. 2001).

The morphology of the HA-uc and HA-c samples is shown in the SEM micrographs (Fig. 3). The HA-uc sample contains needle-like shape crystallites (Fig. 3a). Instead, in the HA-c sample the particles are agglomerated in spherical-like shape aggregates with an average diameter smaller than $200 \mathrm{~nm}$ (Fig. 3b). 

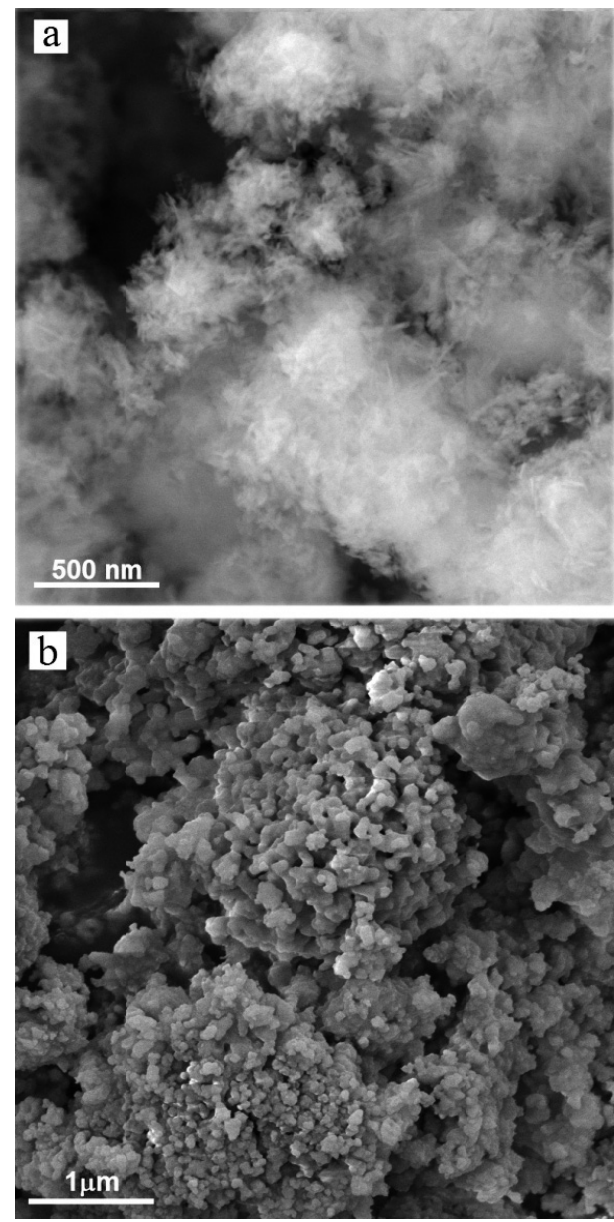

Fig. 3. SEM images of HA-uc (a) and HA-c (b) samples

Nitrogen adsorption/desorption isotherms and pore size distributions of the samples are shown in Fig. 4. Both samples presented type IV isotherm patterns with H3-type hysteresis loop, which are the characteristics of the mesoporous materials. The average pore diameter of the HA-uc and HA-c samples was found to be $3.84 \mathrm{~nm}$ and $1.16 \mathrm{~nm}$, and the mesoporosity of $92.71 \%$ and $89.54 \%$, respectively. These results indicate that both samples were mesoporous with a wide porous distribution, which will allow the facile diffusion of the dye particles into the pores of hydroxyapatite powders. The BET surface area of the HA-uc and HA-c samples was of $325 \mathrm{~m}^{2} / \mathrm{g}$ and $269 \mathrm{~m}^{2} / \mathrm{g}$, while their total pore volume was of $0.357 \mathrm{~cm}^{3} / \mathrm{g}$ and $0.281 \mathrm{~cm}^{3} / \mathrm{g}$, respectively. Therefore, the nanodimensional uncalcined hydroxyapatite would be expected to be able to hold higher amounts of dyes than the calcined nanohydroxyapatite.

Generally, the $\mathrm{pH}$ at the point of zero charge $\left(\mathrm{pH}_{p z c}\right)$ is a characteristic that determines the $\mathrm{pH}$ at which the surface of an adsorbent has net electrical neutrality. The $p H_{\mathrm{pzc}}$ of the HA-uc and HA-c samples was found to be 7.5 and 7.9, respectively, in good agreement with literature data (Bell et al. 1973). Hence, the surface of the HAp samples becomes positive charged for $\mathrm{pH}<p H_{\mathrm{pzc}}$ and negative for $\mathrm{pH}>p H_{p z c}$.

\section{Effect of initial $\mathrm{pH}$}

In order to evaluate the effect of the initial $\mathrm{pH}$ of the dye solutions on the RB19 dye adsorption on the HA-uc and HA-c samples the experiments were carried out within the $\mathrm{pH}$ range of 2-11 keeping all other parameters constant (initial dye concentration $65 \mathrm{mg} / \mathrm{L}$, adsorbent dose $2 \mathrm{~g} / \mathrm{L}$, contact time $3 \mathrm{~h}$, temperature $20^{\circ} \mathrm{C}$ ). As seen in Fig. 5, the removal rate is seen to be higher in acidic $\mathrm{pH}$ media and lower in basic $\mathrm{pH}$ media.

The dye anions adsorption is more favorable when the $\mathrm{pH}$ is lower than the $\mathrm{pH}_{p z c}$ since the HAp surface became positively charged. For removing the RB19 dye the maximum adsorption was found at $\mathrm{pH} 3$, with a dye removal rate of about $95.58 \%$ and $86.95 \%$ for the HA-uc and HA-c samples, respectively. The dye adsorption decreased for the $\mathrm{pH}$ lower than 3 and this might be caused by the beginning of HAp dissolution at very low $\mathrm{pH}$ values (Dorozhkin 2012). The lower uptake rates of dye at very high $\mathrm{H}^{+}$ion concentrations $(\mathrm{pH}<3)$ can be also attributed to the fierce competition between $\mathrm{H}^{+}$ions and dye cations for the appropriate adsorption sites. The protonated active sites can inhibit the dye binding on the HAp surface. In Fig. 5 the uptake rates are seen to decrease with gradual

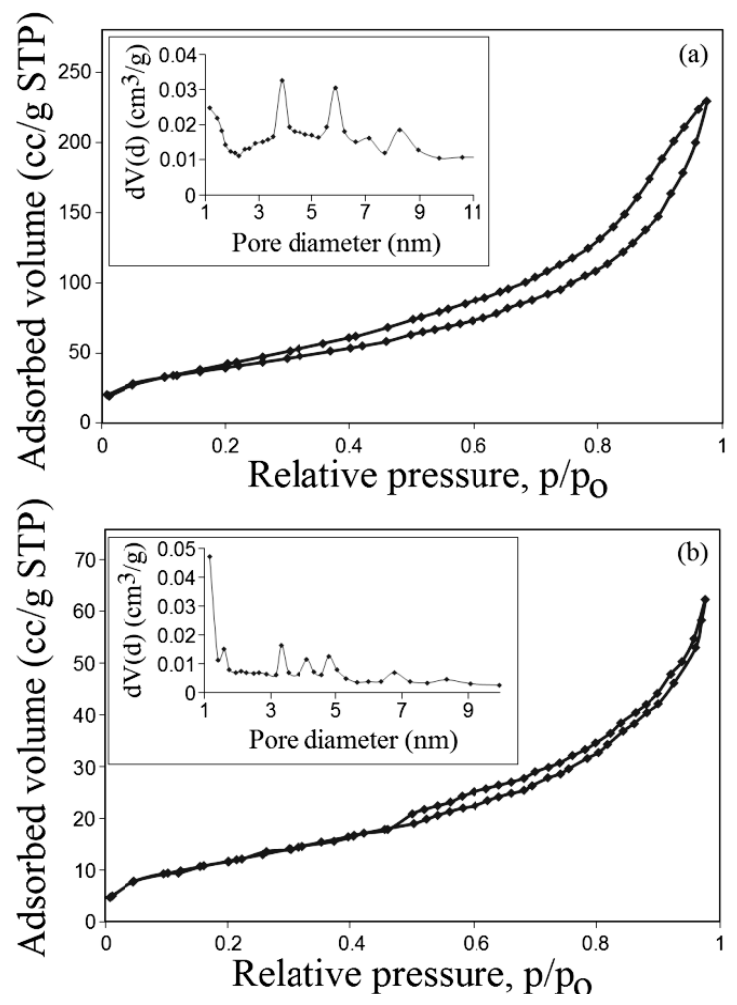

Fig. 4. Pore size distribution of HA-uc (a) and HA-c (b) samples

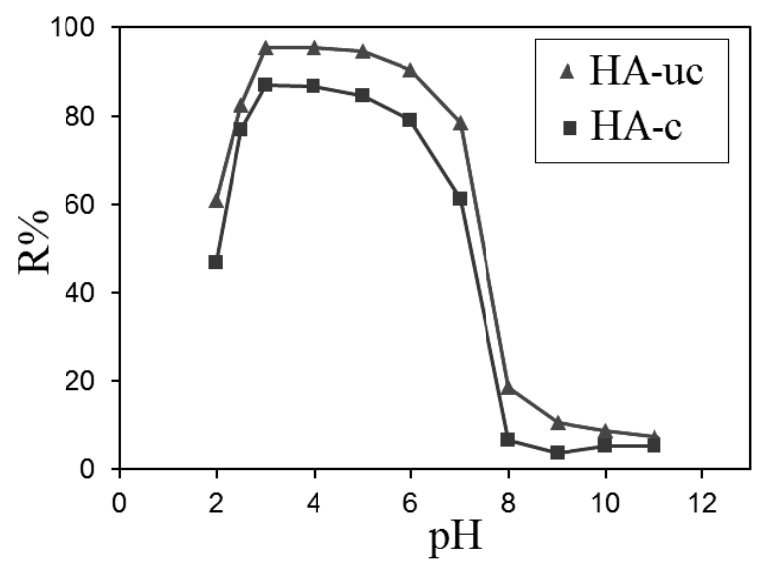

Fig. 5. Effect of initial pH on RB19 dye adsorption on HA-uc and HA-c samples 
increasing of the solution $\mathrm{pH}(\mathrm{pH}>3)$. This is so due to the increasing number of negatively charged sites on the adsorbent surface. The negative surface charge does not favor the adsorption of the dye anions due to the electrostatic repulsion. Similar behavior has been observed for the adsorption of Disperse Blue SBL dye on the HAp (Barka et al. 2008).

The $\mathrm{pH}$ effect on the RB19 dye adsorption on HAp is related to the anionic nature of the RB19 dye containing negative sulfonyl and sulfonic groups and also to the amphoteric nature of the HAp. The literature data predict existence on the HAp surface of the positively $\left(\equiv \mathrm{CaOH}_{2}^{+}\right)$and negatively $\left(\equiv \mathrm{OPO}_{3} \mathrm{H}^{-}\right)$charged sites in acidic and basic $\mathrm{pH}$ media, respectively (Bengtsson and Sjöberg 2009). This means that HAp surfaces exhibit zwitterionic (amphoteric) properties. Therefore, in acidic $\mathrm{pH}$ solution, the RB19 dye adsorption on HAp may be explained to proceed via the electrostatic attraction between the positively charged groups $\left(\equiv \mathrm{CaOH}_{2}^{+}\right)$on the HAp surface and the negatively charged sulfonyl $\left(-\mathrm{OSO}_{3}-\right)$ and sulfonic $\left(-\mathrm{SO}_{3}-\right)$ groups of the dye.

\section{Effect of adsorbent dose}

The effect of adsorbent dose on the RB19 dye removal by the HAp samples was evaluated over the 1-20 g/L range of the adsorbent keeping all other parameters constant (initial $\mathrm{pH} 3$, initial dye concentration $65 \mathrm{mg} / \mathrm{L}$, contact time $3 \mathrm{~h}$, temperature $20^{\circ} \mathrm{C}$ ). Fig. 6 shows the removal rate and adsorption capacity of dye as a function of HAp nanopowder dosage under given conditions. It is clear to see that the increase in the adsorbent dosage results in an obvious increase in the dye adsorption percent. The maximum adsorption capacity was attained at $2 \mathrm{~g} / \mathrm{L}$ adsorbent dose and this amount was used for further experiments. These results could be attributable to the increased surface area of the adsorbent and availability of more adsorption sites. On the other hand, for both samples the adsorption capacity was high at low dosages and reduced at high dosages. The decrease in adsorption capacity with the increase in the adsorbent dosage is mainly attributed to the unsaturation of the adsorption sites through the adsorption process.

\section{Effect of initial dye concentration}

The adsorption of RB19 dye on HAp was studied by changing the initial dye concentration between $0.4-100 \mathrm{mg} / \mathrm{L}$ and keeping constant the other parameters (initial $\mathrm{pH} 3$, adsorbent dose $2 \mathrm{~g} / \mathrm{L}$, contact time $3 \mathrm{~h}$, temperature $20^{\circ} \mathrm{C}$ ). As can be seen

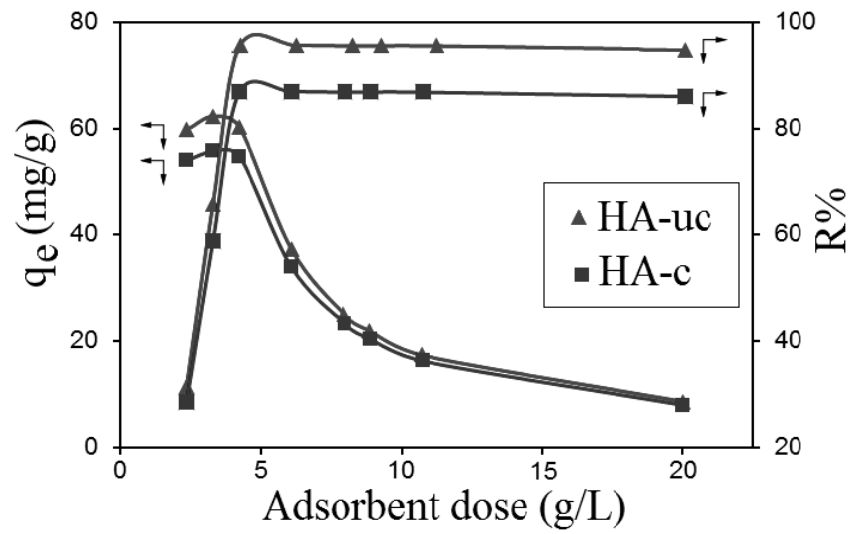

Fig. 6. Effect of adsorbent dose on RB19 dye adsorption on HA-uc and HA-c sample in Fig. 7, the removal rate of RB19 increased with increasing initial dye concentration to a maximum removal rate at initial dye concentration of $65 \mathrm{mg} / \mathrm{L}$ for both samples. However, for initial dye concentration higher than $65 \mathrm{mg} / \mathrm{L}$ there is no distinct difference in $R \%$ values which indicate the fact that the adsorption reaches saturation at high dye concentration because the adsorbent offers a limited number of surface binding sites.

\section{Effect of contact time}

The effect of contact time on the RB19 dye removal (at initial $\mathrm{pH} 3$, adsorbent dose $2 \mathrm{~g} / \mathrm{L}$, initial dye concentration $65 \mathrm{mg} / \mathrm{L}$, temperature $20^{\circ} \mathrm{C}$ ) is depicted in Fig. 8 . The amounts of the dye adsorbed on the both HAp samples increased rapidly in the first 30 min changing then slightly in the following $3 \mathrm{~h}$ when the maximum adsorption is reached. After that no further adsorption occurs with prolonging time which would indicate the reaching of equilibrium, suggesting the monolayer coverage of dye on the outer surface of the HAp. The drastic increase of dye adsorption in the first 30 min may be due to the availability of numerous vacant sites. As the contact time increases, the adsorption sites become unavailable. The remaining vacant surface sites are difficult to be occupied due to repulsive forces between the solute ions on the solid and the bulk phases. The adsorption equilibrium time was prolonged from $30 \mathrm{~min}$ to 180 min on account of the slow pore diffusion of dye ions into the bulk of the HAp.

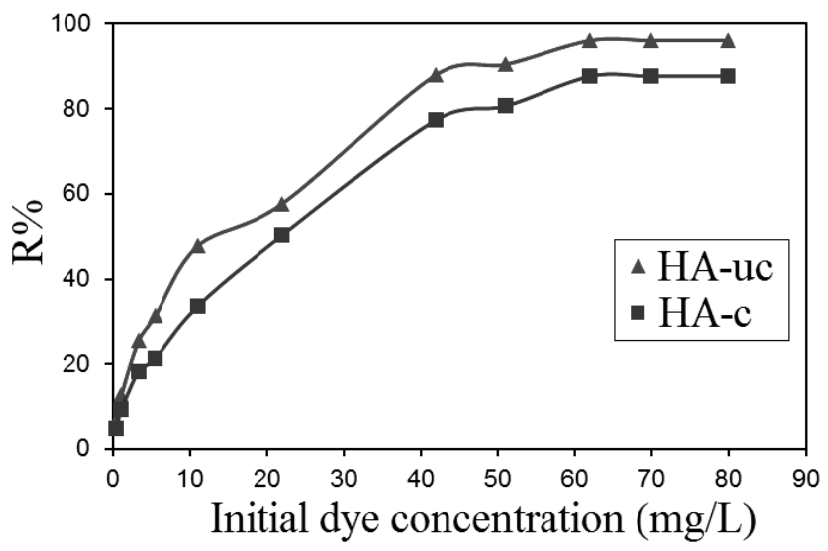

Fig. 7. Effect of initial concentration of RB19 dye on the adsorption process on HA-uc and HA-c samples

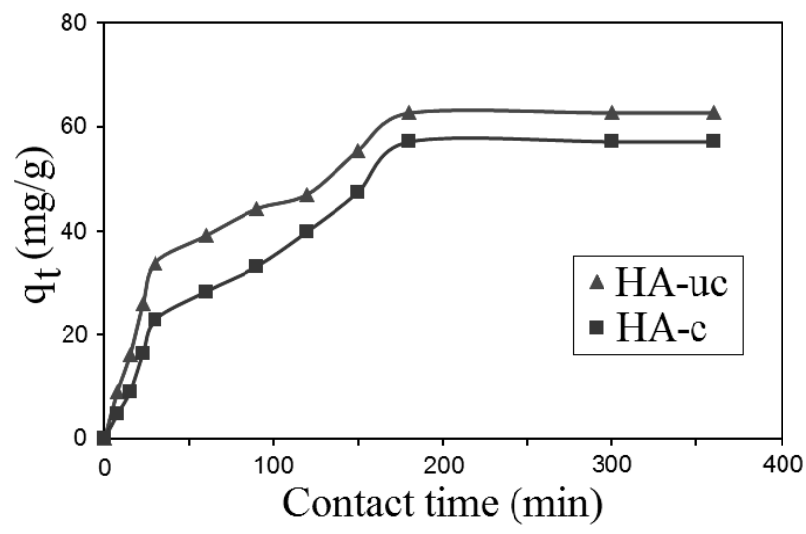

Fig. 8. Effect of contact time on RB19 dye adsorption on HA-uc and HA-c samples 


\section{Effect of temperature}

The temperature effect on the dye adsorption on HAp samples was studied at three different temperatures $\left(20,40\right.$ and $\left.60^{\circ} \mathrm{C}\right)$, keeping constant the other parameters $(\mathrm{pH} \mathrm{3}$, adsorbent dose $2 \mathrm{~g} / \mathrm{L}$, initial dye concentration $65 \mathrm{mg} / \mathrm{L}$, contact time $3 \mathrm{~h}$ ). As shown in Fig. 9, the adsorption capacity decreases with increasing temperature, the maximum adsorption capacity value being obtained at $20^{\circ} \mathrm{C}$ for both HAp samples. This indicates that the RB19 dye adsorption on HAp is controlled by an exothermic process.

\section{Adsorption kinetics models}

Three kinetic models were tested to fit experimental data of the RB19 dye adsorption on HAp samples: pseudo-first order, pseudo-second order and intraparticle diffusion models. Kinetic parameters for above models were calculated from corresponding linear plots presented in Fig. 10 and the results are listed in Table 1.

As shown in Table 1, higher values of the correlation coefficients $\left(R^{2}\right)$ were obtained for the pseudo-second-order model than for the pseudo-first-order model. Apart from this, the linearity of the plots for the pseudo-second order model presented in Fig. 10b for both HAp samples and the close match between the calculated $\left(q_{e, \text { calc }}\right)$ and experimental $\left(q_{e, e x p}\right)$ values of the amount of adsorbed dye (Table 1) confirm the rate of the RB19 dye adsorption process on HAp samples to be well described by a pseudo-second order equation. Therefore, the rate limiting step may be the chemisorption process involving electrostatic interactions. For the sake of comparison, no kinetic model was found in the scientific literature for the adsorption of RB19 dye on HAp from aqueous solution.

Based on the experimental data of the pseudo-second order model, the calculated adsorption capacities $\left(q_{\text {e,calc }}\right)$ values were of $66.22 \mathrm{mg} / \mathrm{g}$ and $60.60 \mathrm{mg} / \mathrm{g}$ for the uncalcined and calcined nanohydroxyapatites, respectively. The decrease of the specific surface area of the calcined hydroxyapatite (HA-c) sample $\left(269 \mathrm{~m}^{2} / \mathrm{g}\right)$ compared to the uncalcined hydroxyapatite (HA-uc) sample $\left(325 \mathrm{~m}^{2} / \mathrm{g}\right.$ ) resulted in a decrease of the adsorption capacity of the RB19 dye. The initial sorption rates $\left(h=k_{2} \cdot q_{e}^{2}\right)$ also decreased with decreasing specific surface area of the HAp samples. Therefore, the uncalcined HAp is able to hold higher amounts of dyes than the calcined HAp.

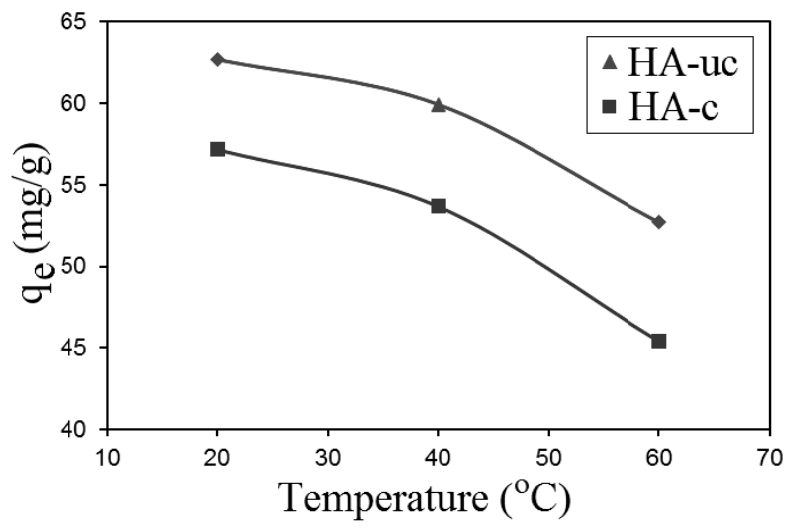

Fig. 9. Effect of temperature on RB19 dye adsorption on HA-uc and HA-c samples
The Weber-Morris equation was used to describe the intraparticle diffusion. The multi-linearity of plots is observed in Fig. 10c, indicating three steps occur during RB19 dye adsorption onto HAp samples. The first sharper stage (the first $30 \mathrm{~min}$ ) could be attributed to rapid diffusion of dye molecules through solution to the external surface of HAp and diffusion of dye molecules through boundary layer to the surface of adsorbent. This rapid external surface adsorption is attributed to the instantaneous utilization of the most readily available adsorption sites on the HAp surface. Generally, the slope of the first linear portion reflects the intraparticle diffusion rate constant. The second stage (from $30 \mathrm{~min}$ to $3 \mathrm{~h}$ ) describes the gradual adsorption of dye, where intraparticle diffusion is the rate limiting. The third stage could be attributed to the equilibrium period, which intraparticle diffusion started to slow down due to extremely low residual dye concentration in solution. The plots of the experimental data in Fig. 10c do not pass through the origin which would suggest that the adsorption involves the intraparticle diffusion, but this is not the only rate-controlling step in the adsorption process. Finally,
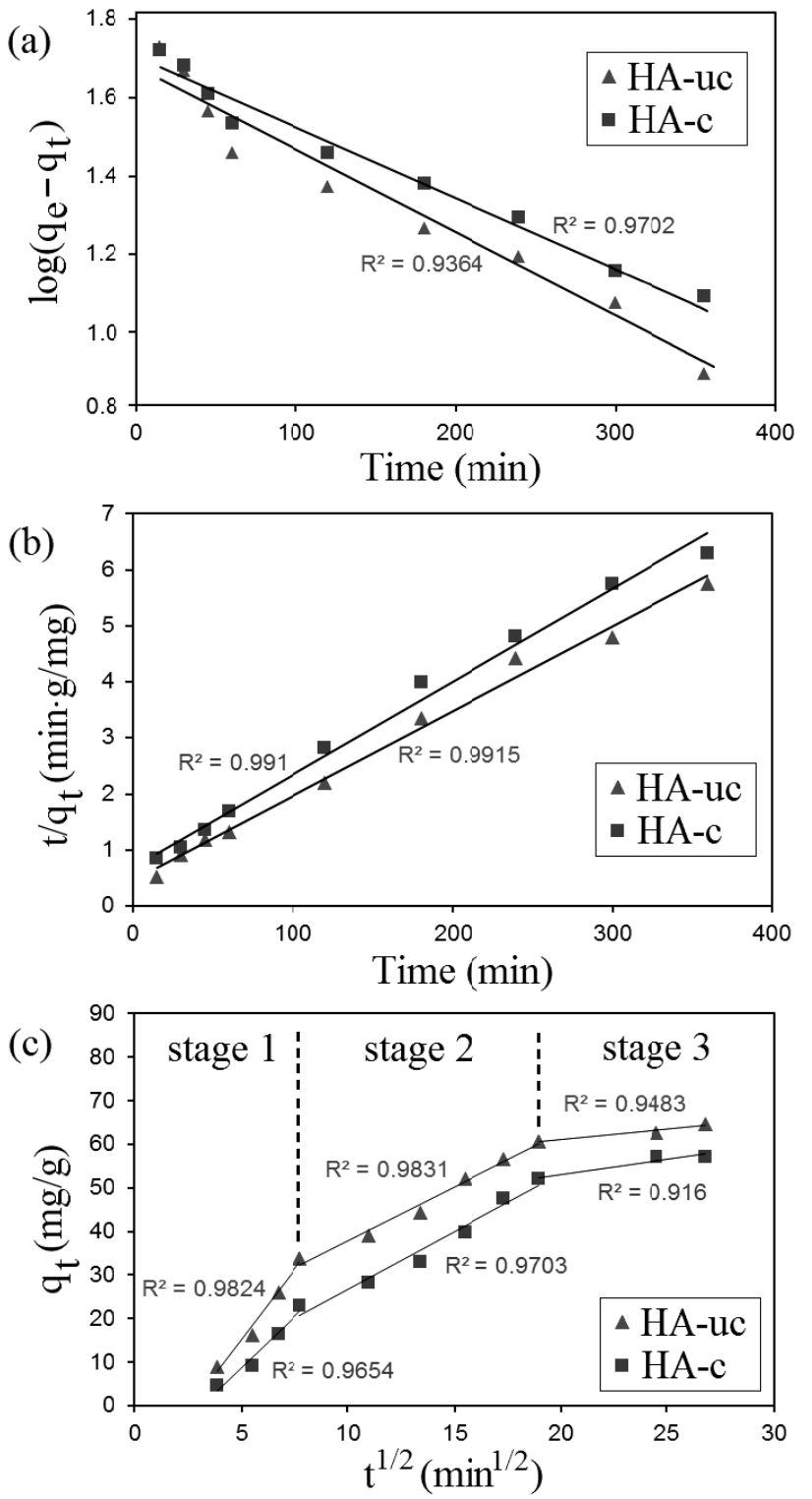

Fig. 10. The pseudo-first order (a), pseudo-second order (b) and intraparticle diffusion (c) kinetic models for RB19 dye adsorption on HA-uc and HA-C samples at $20^{\circ} \mathrm{C}$ 
Table 1. Kinetic parameters for RB19 dye adsorption on HA-uc and HA-c samples at $20^{\circ} \mathrm{C}$

\begin{tabular}{|c|c|c|c|}
\hline Kinetic model & Parameter & HA-uc sample & HA-c sample \\
\hline & $q_{e, \mathrm{exp}}(\mathrm{mg} / \mathrm{g})$ & 62.6834 & 57.1501 \\
\hline \multirow{3}{*}{ Pseudo-first order } & $q_{e, \text { calc }}(\mathrm{mg} / \mathrm{g})$ & 47.5883 & 50.5941 \\
\hline & $k_{1}\left(\min ^{-1}\right)$ & 0.004836 & 0.004145 \\
\hline & $R^{2}$ & 0.9364 & 0.9702 \\
\hline \multirow{4}{*}{ Pseudo-second order } & $q_{e, \text { calc }}(\mathrm{mg} / \mathrm{g})$ & 66.2252 & 60.6061 \\
\hline & $k_{2}(\mathrm{~g} / \mathrm{mg} \cdot \mathrm{min})$ & 0.0005018 & 0.0003910 \\
\hline & $h(\mathrm{mg} / \mathrm{g} \cdot \mathrm{min})$ & 2.2007 & 1.4362 \\
\hline & $R^{2}$ & 0.9915 & 0.9910 \\
\hline \multirow{9}{*}{ Intraparticle diffusion } & $k_{i d, 1}\left(\mathrm{mg} / \mathrm{g} \cdot \mathrm{min}^{1 / 2}\right)$ & 6.4912 & 4.7218 \\
\hline & $c_{1}(\mathrm{mg} / \mathrm{g})$ & 17.319 & 14.779 \\
\hline & $R_{1}^{2}$ & 0.9824 & 0.9654 \\
\hline & $k_{i d, 2}\left(\mathrm{mg} / \mathrm{g} \cdot \mathrm{min}^{1 / 2}\right)$ & 2.4792 & 2.6714 \\
\hline & $c_{2}(\mathrm{mg} / \mathrm{g})$ & 13.07 & 0.0441 \\
\hline & $R_{2}^{2}$ & 0.9831 & 0.9703 \\
\hline & $k_{i d, 3}\left(\mathrm{mg} / \mathrm{g} \cdot \mathrm{min}^{1 / 2}\right)$ & 0.4826 & 0.6846 \\
\hline & $c_{3}(\mathrm{mg} / \mathrm{g})$ & 51.377 & 39.444 \\
\hline & $R_{3}^{2}$ & 0.9483 & 0.9160 \\
\hline
\end{tabular}

it may be concluded that the surface adsorption and intraparticle diffusion were concurrently operating during the adsorption process.

From the pseudo-second order rate constant $\left(k_{2}\right)$ the activation energy $\left(E_{a}\right)$ of the RB19 dye adsorption on HAp samples was estimated by the Arrhenius relationship using the Eq. (6). The Arrhenius plots of $\ln k$, against $1 / T$ for the adsorption of the dye on HAp samples are shown in Fig. 11. The $E_{a}$ values obtained for the RB19 dye adsorption on HA-uc $(20.37 \mathrm{~kJ} / \mathrm{mol})$ and HA-c $(18.01 \mathrm{~kJ} / \mathrm{mol})$ samples were positive thus indicating the feasibility of the adsorption process. Besides, the $E_{a}$ values are lower than $40 \mathrm{~kJ} / \mathrm{mol}$ indicating the rate-limiting step in the RB19 dye adsorption process to be possibly physically controlled.

\section{Adsorption isotherms}

The adsorption data obtained in the dye concentration range of $1-100 \mathrm{mg} / \mathrm{L}$ were correlated with the linear forms of the Langmuir and Freundlich adsorption isotherm models. The isotherms for the systems studied are shown in Fig. 12 and the adsorption isotherm constants computed by Eqs. (7)-(9) listed in Table 2.

The best fitted model was selected based on the determination of the correlation coefficient $R^{2}$. As seen in Table 2, the $R^{2}$ values of the Langmuir isotherm model were higher than those of the Freundlich model meaning that the experimental equilibrium data are better explained by the Langmuir model. This finding supports the assumption that the RB19 dye is adsorbed as a homogeneous monolayer on HAp particles sites. The maximum adsorption capacity $\left(q_{m}\right)$

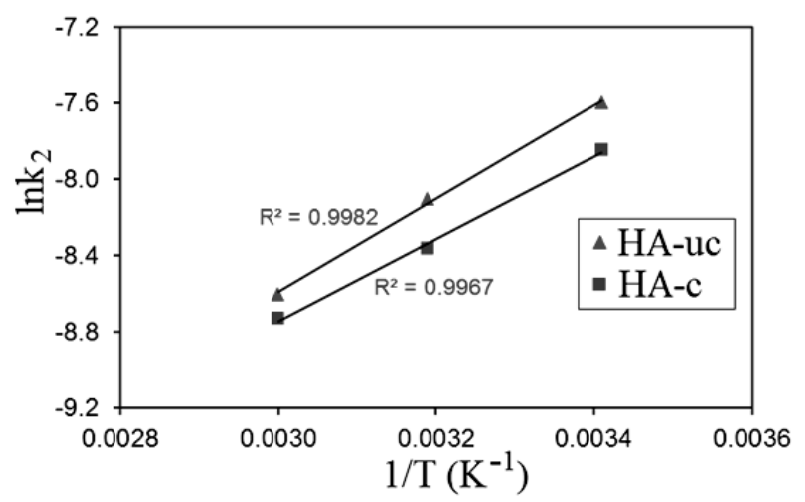

Fig. 11. Arrhenius plot for RB19 dye adsorption on HA-uc and HA-c samples

of uncalcined and calcined HAp samples has been found to be $90.09 \mathrm{mg} / \mathrm{g}$ and $74.97 \mathrm{mg} / \mathrm{g}$, respectively. These values are comparable to the reported ones regarding the RB19 dye adsorption on other adsorbents: $87.72 \mathrm{mg} / \mathrm{g}$ (on magnetite nanoparticles loaded tea waste) (Madrakian et al. 2012), $60 \mathrm{mg} / \mathrm{g}$ (on Basic oxygen furnace slag) (Xue et al. 2009) and $97.1 \mathrm{mg} / \mathrm{g}$ (on wheat bran) (Çiçek et al. 2007).

The values of the separation factor $\left(R_{\mathrm{L}}\right)$ calculated by Eq. (8) were found less than unity at all studied temperatures and therefore the RB19 adsorption on HA-uc and HA-c samples is favorable especially at low temperatures.

The Freundlich constant $n_{F}$ is a measure of the deviation adsorption from linearity (Ho and McKay 1998). As seen in Table 2, the $n_{F}$ values were found to be above unity at all 

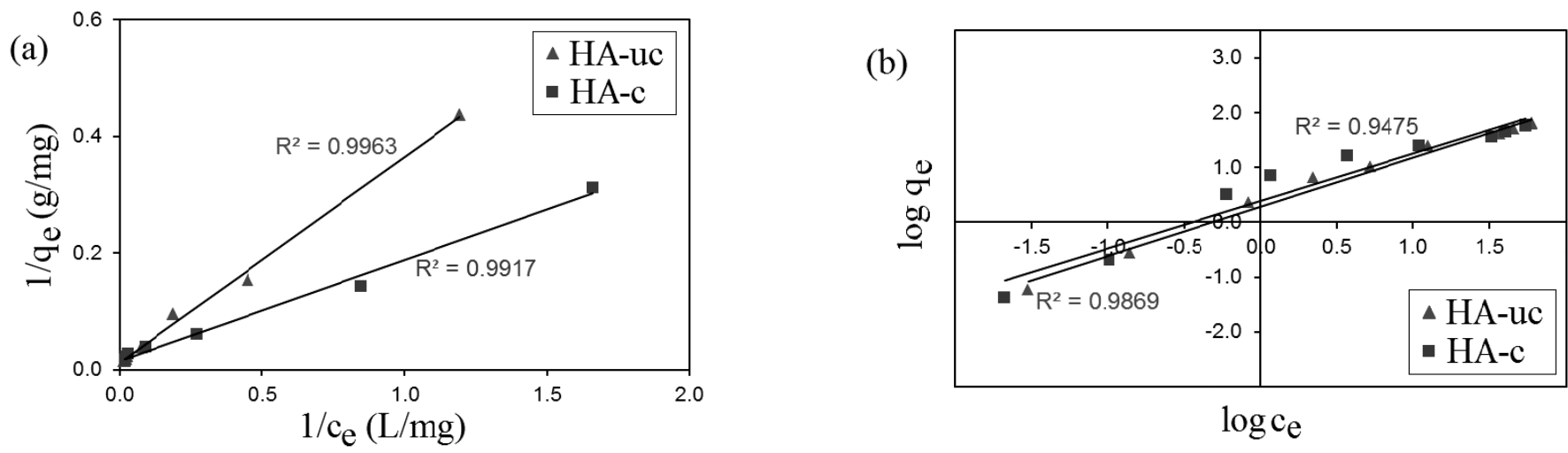

Fig. 12. Langmuir (a) and Freundlich (b) isotherms for RB19 dye adsorption on HA-uc and HA-c samples at $20^{\circ} \mathrm{C}$

Table 2. Adsorption isotherm constants for RB19 dye adsorption on HA-uc and HA-c samples

\begin{tabular}{|c|c|c|c|c|c|c|}
\hline \multirow{3}{*}{$\begin{array}{c}\text { Parameter } \\
T\left({ }^{\circ} \mathrm{C}\right)\end{array}$} & \multicolumn{6}{|c|}{ Sample } \\
\hline & \multicolumn{3}{|c|}{ HA-uc } & \multicolumn{3}{|c|}{$\mathrm{HA}-\mathrm{C}$} \\
\hline & 20 & 40 & 60 & 20 & 40 & 60 \\
\hline \multicolumn{7}{|c|}{ Langmuir isotherm model } \\
\hline$q_{m}(\mathrm{mg} / \mathrm{g})$ & 90.0901 & 82.6446 & 78.7402 & 74.9741 & 65.7895 & 57.4713 \\
\hline$K_{\mathrm{L}}(\mathrm{L} / \mathrm{mg})$ & 0.0299 & 0.0215 & 0.0180 & 0.0617 & 0.0480 & 0.0493 \\
\hline$R_{\mathrm{L}}$ & 0.2945 & 0.3674 & 0.4094 & 0.1685 & 0.2065 & 0.2022 \\
\hline$R^{2}$ & 0.9972 & 0.9989 & 0.9903 & 0.9965 & 0.9912 & 0.9961 \\
\hline \multicolumn{7}{|c|}{ Freundlich isotherm model } \\
\hline$K_{F}\left(m g^{(1-1 / n)} \cdot L^{1 / n} / g\right)$ & 1.9146 & 1.7366 & 1.6188 & 2.2940 & 2.1159 & 2.0003 \\
\hline$n_{\mathrm{F}}$ & 1.1404 & 1.1348 & 1.1184 & 1.1695 & 1.1527 & 1.1489 \\
\hline $1 / n_{\mathrm{F}}$ & 0.8769 & 0.8812 & 0.8941 & 0.8551 & 0.8675 & 0.8704 \\
\hline$R^{2}$ & 0.9882 & 0.9986 & 0.9885 & 0.9597 & 0.9811 & 0.9861 \\
\hline
\end{tabular}

studied temperatures, the RB19 dye adsorption on HA-uc and HA-c samples being therefore a physical process. The highest values of $n_{F}$ at equilibrium for both HAp samples were noticed at $20^{\circ} \mathrm{C}$, indicating thus a favorable adsorption at low temperature. The obtained $1 / n_{F}$ values below unity are a measure of the adsorption intensity or surface heterogeneity indicating thus a normal Langmuir isotherm.

\section{Conclusions}

Two types of nanohydroxyapatite (uncalcined and calcined) samples have been used successfully as adsorbents for removing the Reactive Blue 19 dye from aqueous solution. In the batch system, the maximum dye uptake of about 95.58\% and $86.95 \%$ for the uncalcined and calcined HAp, respectively, was noticed at $\mathrm{pH} 3$ and $20^{\circ} \mathrm{C}$, after $3 \mathrm{~h}$ of contact time. The adsorption kinetics and isotherms studies indicated that the adsorption process obeyed the pseudo-second order kinetics and Langmuir model. External surface adsorption and intraparticle diffusion may take place according to intraparticle diffusion model. The maximum adsorption capacity of uncalcined and calcined nanohydroxyapatite samples has been found to be $90.09 \mathrm{mg} / \mathrm{g}$ and $74.97 \mathrm{mg} / \mathrm{g}$, respectively. The research carried out in this paper suggests that nanohydroxyapatite, especially as the uncalcined form, acts an efficient and eco-friendly adsorbent for the removal of the Reactive Blue 19 dye from aqueous solutions, being a promising alternative for eliminating this dye from industrial wastewaters.

\section{References}

Allen, S.J. \& Koumanova, B. (2005). Decolourisation of water/ /wastewater using adsorption (review), Journal of the University of Chemical Technology and Metallurgy, 40, pp. 175-192.

Barka, N., Qourzal, S., Assabbane, A., Nounah, A. \& Aît-Ichou, Y. (2008). Adsorption of Disperse Blue SBL dye by synthesized poorly crystalline hydroxyapatite, Journal of environmental sciences (China), 20, pp. 1268-1272.

Bell, L.C., Posner, A.M. \& Quirk, J.P. (1973). The point of zero charge of hydroxyapatite and fluorapatite in aqueous solutions, Journal of Colloid and Interface Science, 42, pp. 250-261.

Bengtsson, A. \& Sjöberg, S. (2009). Surface complexation and proton-promoted dissolution in aqueous apatite systems, Pure and Applied Chemistry, 81, pp. 1569-1584.

Bina, B., Amin, M.M., Rashidi, A. \& Pourzamani, H. (2012). Benzene and toluene removal by carbon nanotubes from 
aqueous solution, Archives of Environmental Protection, 38, 1, pp. 3-25.

Çiçek, F., Özer, D., Özer, A. \& Özer, A. (2007). Low cost removal of reactive dyes using wheat bran, Journal of Hazardous Materials, 146, pp. 408-416.

Ciobanu, G., Carja, G. \& Ciobanu, O. (2008). Use of SAPO-5 zeolite-filled polyurethane membranes in wastewater treatment, Desalination, 222, 1-3, pp. 197-201.

Ciobanu, G., Ignat, D., Carja, G. \& Luca, C. (2009). Hydroxyapatite/ /polyurethane composite membranes for lead ions removal, Environmental Engineering and Management Journal, 8, 6, pp. 1347-1350.

Ciobanu, G., Ilisei, S., Harja, M. \& Luca, C. (2013). Removal of Reactive Blue 204 dye from aqueous solutions by adsorption onto nanohydroxyapatite, Science of Advanced Materials, 5, pp. 1090-1096.

Ciobanu, G., Harja, M., Rusu, L., Mocanu, A.M. \& Luca, C. (2014). Acid Black 172 dye adsorption from aqueous solution by hydroxyapatite as low-cost adsorbent, Korean Journal of Chemical Engineering, 31, pp. 1021-1027.

Dorozhkin, S.V. (2009). Calcium orthophosphates in nature, biology and medicine, Materials, 2, pp. 399-498.

Dorozhkin, S.V. (2012). Dissolution mechanism of calcium apatites in acids: A review of literature, World Journal of Methodology, 2, pp. $1-17$.

Elliott, J.C. (1994). Structure and Chemistry of the Apatites and Other Calcium Orthophosphates, Elsevier, Amsterdam 1994.

Forgacs, E., Cserháti, T. \& Oros, G. (2004). Removal of synthetic dyes from wastewaters: a review, Environment International, 30 , pp. 953-971.

Freundlich, H.M.F. (1906). Uber die adsorption in Losungen, Zeitschrift fur Physikalische Chemie, 57, pp. 385-470.

Gupta, V.K., Carrott, P.J.M., Ribeiro Carrott, M.M.L. \& Suhas, P. (2009). Low-cost adsorbents: growing approach to wastewater treatment - a review, Critical Reviews in Environmental Science and Technology, 39, pp. 783-842.

Hao, O.J., Kim, H. \& Chang, P.C. (2000). Decolorization of wastewater, Critical Reviews in Environmental Science and Technology, 30, pp. 449-505.

Harja, M., Barbuta, M., Rusu, L., Munteanu, C., Buema, G. \& Doniga, E. (2011). Simultaneous removal of Astrazone blue and lead onto low cost sorbents based on power plant ash, Environmental Engineering and Management Journal, 10, pp. 341-347.

Ho, Y.S. \& McKay, G. (1998). Sorption of dye from aqueous solution by peat, Chemical Engineering Journal, 70, pp. 115-124.
Khan, M.N. \& Sarwar, A. (2007). Determination of points of zero charge of natural and treated adsorbents, Surface Review and Letters, 14, pp. 461-469.

Kahraman, S., Kuru, F., Dogan, D. \& Yesilada, O. (2012). Removal of Indigo Carmine from an aqueous solution by fungus Pleurotus ostreatus, Archives of Environmental Protection, 38, 3, pp. 51-57.

Kaušpèdienė, D., Kazlauskienè, E., Česūnienè, R., Gefenienė, A., Ragauskas, R. \& Selskienè, A. (2013). Removal of the phthalocyanine dye from acidic solutions using resins with the polystyrene divinylbenzene matrix, Chemija, 24, 3, pp. 171-181.

Lagergren, S. (1898). Zur theorie der sogenannten adsorption geloester stoffe, Kungliga Svenska Vetenskapsakad, Handlingar, 24, pp. 1-39.

Langmuir, I. (1916). The constitution and fundamental properties of solids and liquids, Journal of the American Chemical Society, 38, pp. 2221-2295.

Lin, K., Pan, J., Chen, Y., Cheng, R. \& Xu, X. (2009). Study the adsorption of phenol from aqueous solution on hydroxyapatite nanopowders, Journal of Hazardous Materials, 161, pp. 231-240.

Madrakian, T., Afkhami, A. \& Ahmadi, M. (2012). Adsorption and kinetic studies of seven different organic dyes onto magnetite nanoparticles loaded tea waste and removal of them from wastewater samples, Spectrochimica Acta Part A: Molecular and Biomolecular Spectroscopy, 99, pp. 102-109.

Raynaud, S., Champion, E., Bernache-Assollant, D. \& Laval, J.P. (2001). Determination of calcium/phosphorus atomic ratio of calcium phosphate apatites using X-ray Diffractometry, Journal of the American Ceramic Society, 84, pp. 355-366.

Unuabonah, E.I., Adebowale, K.O. \& Olu-Owolabi, B.I. (2007). Kinetic and thermodynamic studies of the adsorption of lead(II) ions onto phosphate-modified kaolinite clay, Journal of Hazardous Materials, 144, pp. 386-395.

Webber, E.J. \& Stickney, V.C. (1993). Hydrolysis kinetics of Reactive Blue 19-Vinyl Sulfone, Water Research, 27, pp. 63-67.

Weber Jr., W.J. \& Morris, J.C. (1963). Kinetics of adsorption on carbon from solution, Journal of the Sanitary Engineering Division, 89, pp. 31-59.

Weber, T.W. \& Chakravorti, R.K. (1974). Pore and solid diffusion models for fixed bed adsorbers, Journal of American Institute of Chemical Engineers, 20, pp. 228-238.

Xue, Y., Hou, H. \& Zhu, S. (2009). Adsorption removal of reactive dyes from aqueous solution by modified basic oxygen furnace slag: Isotherm and kinetic study, Chemical Engineering Journal, 147 , pp. 272-279. 